\title{
Antiprotozoal activities of marine polyether triterpenoids
}

\author{
Ana R. Díaz-Marrero ${ }^{1, \neq}$, Atteneri López-Arencibia ${ }^{2, \neq}$, Carlos J. Bethencout-Estrella ${ }^{2}$, Francisco Cen- \\ Pacheco $^{1,3}$, Ines Sifaoui ${ }^{2}$, Alberto Hernández Creus ${ }^{4}$, María Clara Duque-Ramírez ${ }^{2}$, María L. Souto ${ }^{1,5}$, \\ Antonio Hernández Daranas ${ }^{1,6}$, Jacob Lorenzo-Morales ${ }^{2}$, José E. Piñero ${ }^{2, *}$ and José J. Fernández ${ }^{1,5 *}$ \\ 1 Instituto Universitario de Bio-Orgánica Antonio González (IUBO AG), Centro de Investigaciones Biomédicas de Canarias \\ (CIBICAN), Universidad de La Laguna (ULL), Avda. Astrofísico F. Sánchez 2, 38206 La Laguna, Tenerife, Spain \\ 2 Instituto Universitario de Enfermedades Tropicales y Salud Pública de Islas Canarias (IETSPC), Universidad de La Laguna \\ (ULL), Avda. Astrofísico F. Sánchez s/n, 38206 La Laguna, Tenerife, Spain \\ 3 Facultad de Bioanálisis, Campus-Veracruz, Universidad Veracruzana (UV), Veracruz 91700, Mexico \\ 4 Departamento de Química, Instituto de Universitario de Nanomateriales, Universidad de La Laguna (ULL), Avda. \\ Astrofísico F. Sánchez s/n, 38206 Tenerife, Spain \\ 5 Departamento de Química Orgánica, Universidad de La Laguna (ULL), Avda. Astrofísico F. Sánchez 2, 38206 La Laguna, \\ Tenerife, Spain \\ 6 Instituto de Productos Naturales y Agrobiología (IPNA), Consejo Superior de Investigaciones Científicas (CSIC), Avda. \\ Astrofísico F. Sánchez s/n, 38206 Tenerife, Spain \\ ₹ These authors contributed equally to this manuscript
}

Corresponding author: jpinero@ull.edu.es (J.E.P.); jjfercas@ull.edu.es (J.J.F.); Tel.: +34-922-318-485 (J.E.P.); +34-922318-586 (J.J.F.)

\begin{abstract}
Chagas disease and leishmaniasis are tropical neglected diseases caused by kinetoplastids protozoan parasites of Trypanosoma and Leishmania genera, and a public health burden with high morbidity and mortality rates in developing countries. Among difficulties with their epidemiological control, a major problem is their limited and toxic treatments to attend the affected populations; therefore, new therapies are needed in order to find new active molecules. In this work, sixteen Laurencia oxasqualenoid metabolites, natural compounds 111 and semisynthetic derivatives 12-16, were tested against Leishmania amazonensis, Leishmania donovani and Trypanosoma cruzi. The results obtained point out that eight substances possess potent activities, with IC 50 values in the range of 5.40 to $46.45 \mu \mathrm{M}$. The antikinetoplastid action mode of the main metabolite dehydrothyrsiferol (1) was developed, also supported by AFM images.

The semi-synthetic active compound 28-iodosaiyacenol B (15) showed an $\mathrm{IC}_{50} 5.40 \mu \mathrm{M}$ against Leishmania amazonensis, turned to be non-toxic against the murine macrophage cell line J774A.1 $\left(\mathrm{CC}_{50}>100\right)$. These values are comparable with the reference compound miltefosine $\mathrm{IC}_{50} 6.48 \pm 0.24$ and $\mathrm{CC}_{50} 72.19 \pm 3.06 \mu \mathrm{M}$, suggesting that this substance could be scaffold for development of new antikinetoplastid drugs.
\end{abstract}

Key Words: Marine natural products; Marine polyether; Oxasqualenoids; Kinetoplastids, Laurencia; Leishmania; Leishmanicidal; Trypanosoma; Trypanocidal. 


\section{Introduction}

Protozoal diseases, such as leishmaniasis and American trypanosomiasis (Chagas disease) are the cause of considerable morbidity throughout the world, affecting millions every year [1]. Leishmaniasis is a disease caused by parasites of the genus Leishmania and is transmitted by the bite of a female phlebotomine sand fly. Leishmaniasis can manifest in three different forms: cutaneous and mucocutaneous, caused by Leishmania amazonensis, and visceral, originated by infections with $L$. donovani [2]. Chagas disease affects around 8 million people worldwide and the available treatment is just effective in the acute phase of the illness. Current therapy against these diseases involves the use of benznidazole or nifurtimox (Chagas) and amphotericin B (Leishmania), which present toxic side effects and the risk of resistantstrains emergence [3].

Interestingly till date, those diseases have remained significant, despite our advances in antimicrobial chemotherapy and supportive care, mostly due to problems associated with chemotherapeutic interventions. In fact, the treatment of these infections has been undermined by resistance, variable efficacy between strains or species, toxicity, parenteral administration, requirement for long courses of administration and adverse effects and cost. In recent years, studies on natural compounds have taken relevance, and among them marine organisms are being evaluated for the search of new potential antiparasitic agents.

Within this marine chemical arsenal, molecules with exciting biological activities include polyether compounds, such as the squalene-derived metabolites isolated from the red alga Laurencia. In fact, a large number of triterpene polyether compounds with significant structural and pharmacological diversity have been identified. Within this family, compounds with moderate to potent cytotoxic activity have been described. These family include the SerThr Protein phosphatase type 2A (PP2A) and integrin inhibitory substances [4-8].

In this study, sixteen oxasqualenoids (Figure 1), either isolated from the natural source, the red alga Laurencia viridis, or obtained by semi-synthetic procedures from the lead compound dehydrothyrsiferol (DT) (1), were evaluated in search for trypanocidal or leishmanicidal activity, in order to find new active principles to replace current treatments or to be used as model for their development of new drugs for these diseases. 


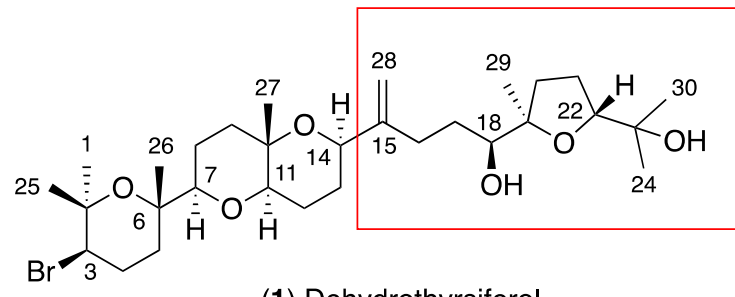

(1) Dehydrothyrsiferol<smiles>[R]=CCC(=C)CC[C@@H](O)[C@]1(C)CC[C@@H](O)[C@@H](C)O1</smiles>

(3) lubol

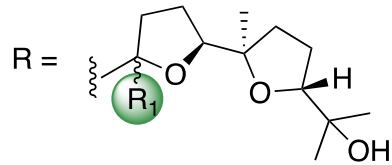

(6) Saiyacenol $\mathrm{AR}_{1}=\mathrm{CH}_{3}$ (15S)

(7) Saiyacenol B $\mathrm{R}_{1}=\mathrm{CH}_{3}(15 R)$

(8) 28-Hydroxysaiyacenol $A R_{1}=\mathrm{CH}_{2} \mathrm{OH}$ (15R)

(9) 28-Hydroxysaiyacenol $B \mathrm{R}_{1}=\mathrm{CH}_{2} \mathrm{OH}$ (15S)

(14) 28-lodosaiyacenol $A R_{1}=C_{2} l$ (15S)

(15) 28-lodosaiyacenol $\mathrm{B} \mathrm{R}_{1}=\mathrm{CH}_{2} \mathrm{l}(15 R)$<smiles>C=C(C)[C@@H]1CC[C@@](C)([C@H]2CC[C@]3(C)O[C@H](C(=C)CC[C@H](O)[C@]4(C)CC[C@H](C(C)(C)O)O4)CC[C@H]3O2)O1</smiles>

(5) 1,2-Dehydropseudodehydrothyrsiferol<smiles></smiles>

(2) Thyrsiferol<smiles></smiles>

(12) 18-Sulphatedehydrothyrsiferol<smiles>CC(C)(O)[C@@H]1CC[C@H]([C@H](O)CCC(O)(CO)[13CH]=[13CH2])O1</smiles>

(16) 28-Hydroxythyrsiferol

(13) 18-Ketodehydrothyrsiferol

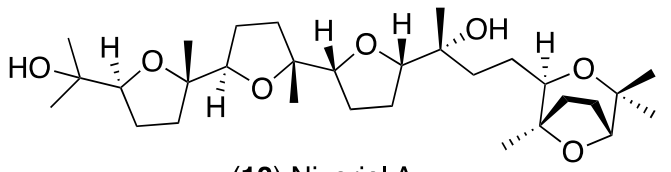

(10) Nivariol A<smiles>CC1(C)OC(=O)CCC1O[C@H]1CC[C@]2(C)[C@@H](Br)CC[C@H]2O1</smiles>

(11) Adejene B

Figure 1. Structure of the natural (1-11) and semi-synthetic (12-16) tested terpenoid polyether compounds.

\section{Results and Discussion}

\subsection{Source of the oxasqualenoid compound collection}

The samples of oxasqualenoids: dehydrothyrsiferol (DT) (1) [9]; thyrsiferol (2) [10]; iubol (3) [11]; 22-hydroxydehydrothyrsiferol (4) [11], 1,2-dehydropseudodehydrothyrsiferol (5) [11]; saiyacenols A and B (6 and 7) [12]; 28-hydroxysaiyacenol A y B (8 and 9) [13], nivariol A (10) [14], and the truncated metabolite adejene $B$ (11) [15] were obtained in our research group from different collections of the marine red algae Laurencia viridis during the period 20142018. Only DT (1) and thyrsiferol (2) had been previously obtained from different Laurencia species, L. pinnatifida [9] and L. thyrsifera [10], respectively. In addition, the semi-synthetic congeners: 18-sulphatedehydrothyrsiferol (12); 18-ketodehydrothyrsiferol (13); 28iodosaiyacenols A and B (14 and 15) and 28-hydroxythyrsiferol (16) were prepared from the main metabolite DT (1) [16] based on solubility-driven criteria. 


\subsection{Antiparasitic effects}

\subsubsection{Antikinetoplastid activities}

Initially, eleven natural compounds isolated from specimens of $L$. viridis and five semisynthetic compounds prepared from DT (1) were evaluated for their anti-protozoal activity against three different cell types namely Leishmania amazonensis (cutaneous and mucocutaneous leishmaniasis), Leishmania donovani (visceral leishmaniasis) and Trypanosoma cruzi (Chagas disease). The antikinetoplastid results are summarized in Table 1. Among the tested molecules, six were effective against $L$. amazonensis with an $\mathrm{IC}_{50}$ ranged from $5.40 \pm 0.13 \mu \mathrm{M}$ for 28-Iodosaiyacenol-B (15) to $20.39 \pm 2.90 \mu \mathrm{M}$ for 28-lodosaiyacenol A (14). Leishmania donovani was inhibited by four compounds with $\mathrm{IC}_{50}$ values ranged from $18.08 \pm 2.62$ to $33.90 \pm 1.74 \mu \mathrm{M}$ for iubol (3) and 28-iodosaiyacenol A (14), respectively. Meanwhile, Trypanosoma cruzi was the most resistant parasite with only four effective compounds, namely, iubol (3) with an IC 50 of $9.20 \pm 1.16 \mu \mathrm{M}$; DT (1) with an IC 50 of $9.45 \pm 0.46$ $\mu \mathrm{M}, 18$-ketodehydrothyrsiferol (13) with an $\mathrm{IC}_{50}$ of $11.02 \pm 2.60 \mu \mathrm{M}$, and saiyacenol-A (6) with an $\mathrm{IC}_{50}$ of $13.75 \pm 2.28 \mu \mathrm{M}$.

Table 1. Anti-kinetoplatid effect of natural and semi-synthetic oxasqualenoids 1-16 against Leishmania amazonensis, Leishmania donovani and Trypanosoma cruzi. $\mathrm{IC}_{50}$ are reported in $\mu \mathrm{M}$. Toxicity against murine macrophage J774.A1 ( $\left.\mathrm{CC}_{50}\right)$.

\begin{tabular}{|c|c|c|c|c|}
\hline Compounds & $\begin{array}{l}\text { L. amazonensis } \\
\text { (Promastigote) }\end{array}$ & $\begin{array}{c}\text { L. donovani } \\
\text { (Promastigote) }\end{array}$ & $\begin{array}{c}\text { T. cruzi } \\
\text { (Epimastigote) }\end{array}$ & $\begin{array}{c}\text { Murine macrophage } \\
\text { J774A.1 }\end{array}$ \\
\hline 1 & $8.36 \pm 0.77$ & $28.26 \pm 1.74$ & $9.45 \pm 0.46$ & $28.77 \pm 3.10$ \\
\hline 2 & NA & NA & NA & $>100$ \\
\hline 3 & $7.00 \pm 0.22$ & $18.08 \pm 2.62$ & $9.20 \pm 1.16$ & $7.72 \pm 0.22$ \\
\hline 4 & $34.65 \pm 0.22$ & NA & NA & $>100$ \\
\hline 5 & NA & NA & NA & $>100$ \\
\hline 6 & $12.96 \pm 1.84$ & NA & $13.75 \pm 2.28$ & $59.91 \pm 8.50$ \\
\hline 7 & $10.32 \pm 1.09$ & NA & NA & $>100$ \\
\hline 8 & NA & NA & NA & $>100$ \\
\hline 9 & NA & NA & NA & $>100$ \\
\hline 10 & NA & NA & NA & $>100$ \\
\hline 11 & NA & NA & NA & $>100$ \\
\hline 12 & NA & NA & NA & $>50$ \\
\hline 13 & $38.53 \pm 9.28$ & $46.45 \pm 2.26$ & $11.02 \pm 2.60$ & $23.37 \pm 1.76$ \\
\hline 14 & $20.39 \pm 2.90$ & $33.90 \pm 1.74$ & NA & $29.45 \pm 0.20$ \\
\hline 15 & $5.40 \pm 0.13$ & $16.18 \pm 0.22$ & NA & $>100$ \\
\hline $16^{1}$ & NA & NA & NA & $>100$ \\
\hline Miltefosine * & $6.48 \pm 0.24$ & $3.32 \pm 0.27$ & & $72.19 \pm 3.06$ \\
\hline Benznidazole* & & & $6.94 \pm 1.94$ & $400 \pm 4.00$ \\
\hline
\end{tabular}

* Reference compounds.

${ }^{1}$ These values correspond to a synthetic sample that contain a mixture of $16 R$ and 165 stereoisomers.

NA: Not active at the maximum concentration tested $200 \mu \mathrm{M}$ against parasites.

Regarding the reference drugs to treat Leishmaniasis and Chagas disease, we have evaluated miltefosine and benznidazole, respectively, in order to compare with our compounds. Miltefosine showed an $\mathrm{IC}_{50}$ of $6.48 \pm 0.24 \mu \mathrm{M}$ against $L$. amazonensis and $3.32 \pm 0.27 \mu \mathrm{M}$ 
against $L$. donovani with a $\mathrm{CC}_{50}$ of $72.19 \pm 3.06 \mu \mathrm{M}$, and benznidazole an $\mathrm{IC}_{50}$ of $6.94 \pm 1.94$ $\mu \mathrm{M}$ with a $\mathrm{CC}_{50}$ of $400 \pm 4 \mu \mathrm{M}$ [17].

\subsubsection{Mechanisms of cell death}

DT (1) was selected as candidate molecule to analyze its mode of action, based on the antiparasitic results observed and the fact that 1 the major metabolite in the red alga. $L$. amazonensis and T. cruzi were incubated with the IC $\mathrm{C}_{90}$ of DT (1), $29.06 \mu \mathrm{M}$ and $63.94 \mu \mathrm{M}$, respectively. The $\mathrm{IC}_{90}$ value was used to increase the population of affected parasites and to reduce the experimental time. As observed in Figure 2, after $24 \mathrm{~h}$ of incubation, treated cells show a higher number of cells with strong blue staining in the nucleus for both $L$. amazonensis and $T$. cruzi. The staining in the nucleus corresponds with the process of chromatin condensation, a very common event on cells suffering an apoptosis-like cell death. Thus, DT (1) caused chromatin condensation in treated cells. 

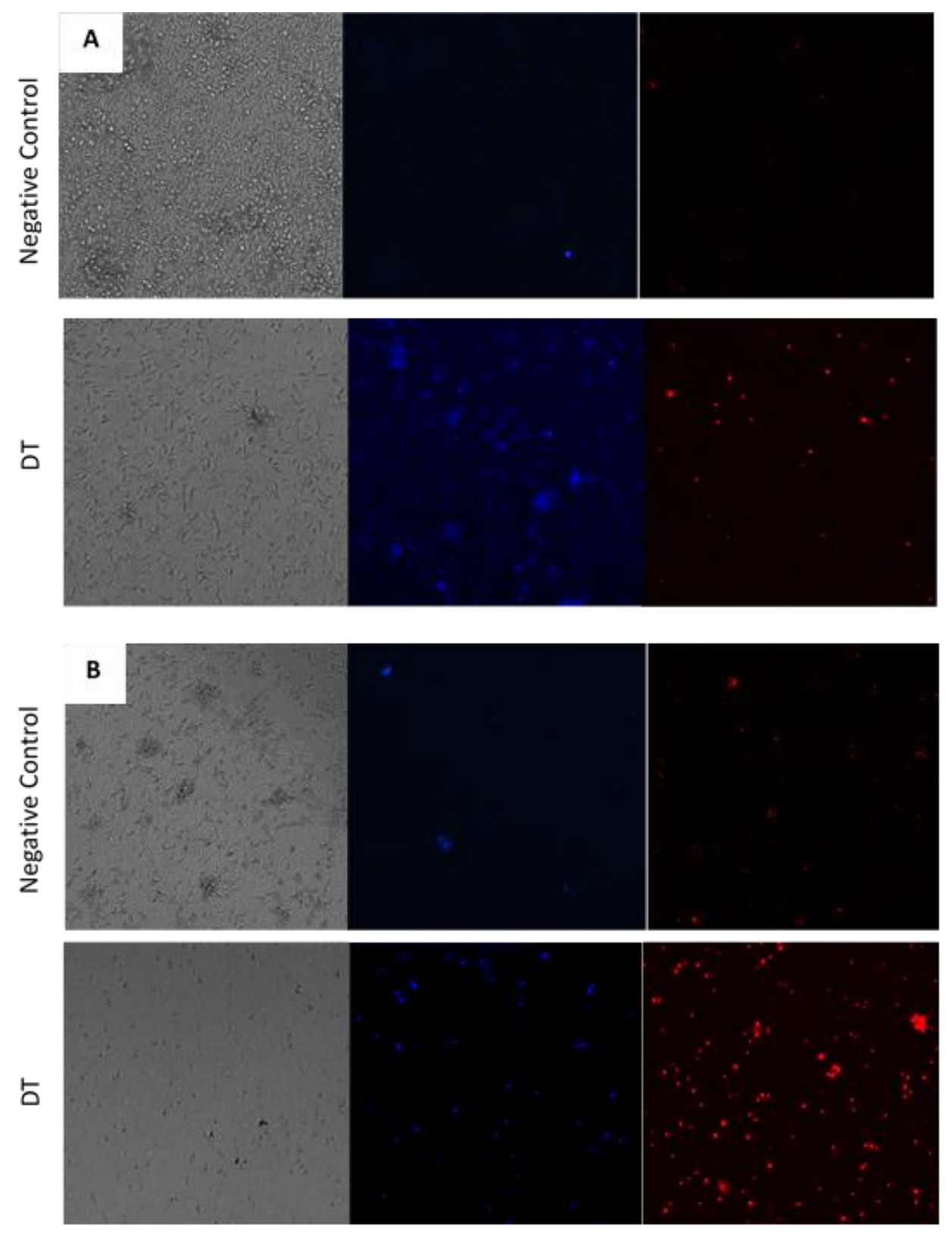

Figure 2. Leishmania amazonensis (A) and Trypanosoma cruzi (B) incubated with $\mathrm{IC}_{90}$ of DT (1) and the evolution of chromatin condensation observed after $24 \mathrm{~h}$. Hoechst stain is different in control cells, where uniformly faintblue nuclei are observed, and in treated cells, where the nuclei are bright blue. Red fluorescence corresponds to the propidium iodide stain. Images (20X) are showing chromatin condensation (blue) in treated cells. Images (20X) are representative of the cell population observed in the performed experiments. Images were obtained using an EVOS FL Cell Imaging System AMF4300, Life Technologies, USA.

DT (1) caused plasma membrane permeability in treated cells. As observed in Figure 3, after 24 hours of incubation of the parasite (Leishmania and Trypanosoma) with the appropriate IC 90 of DT (1), the treated cells show a higher green fluorescence that confirms the plasmatic membrane damage. Even thought, the cell integrity is still maintained. 

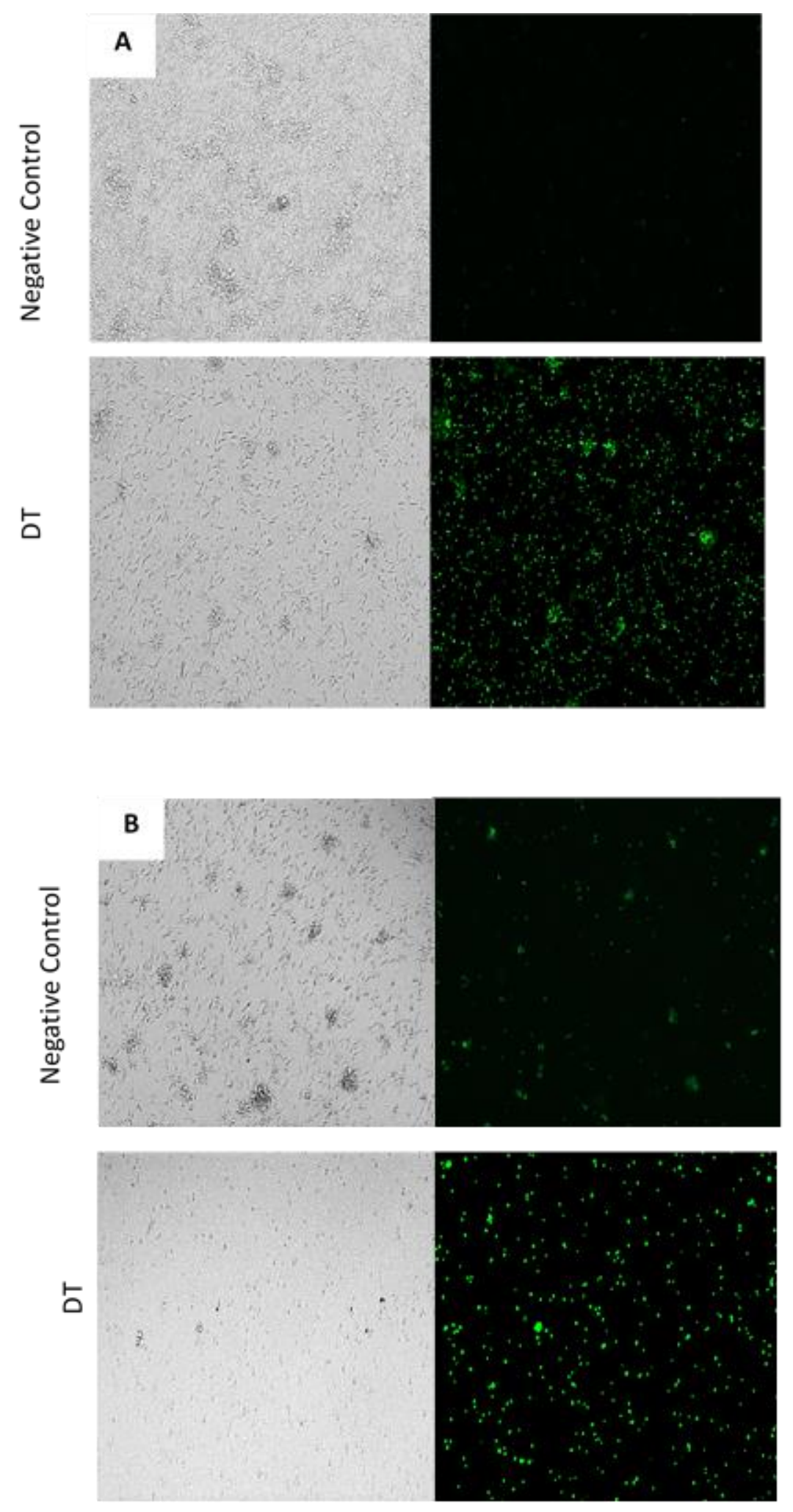

Figure 3. Leishmania amazonensis (A) and Trypanosoma cruzi (B) incubated with I $\mathrm{C}_{90}$ of DT (1) and the evolution of chromatin condensation observed after $24 \mathrm{~h}$. Permeation of the cell plasma membrane to dye SYTOX ${ }^{\circledR}$ green caused by addition of DT (1) at IC 90 for $24 \mathrm{~h}$. DT (1) was added to cells $\left(10^{6}\right.$ cells $\left./ \mathrm{mL}\right)$ in the presence of $1 \mu \mathrm{M}$ SYTOX ${ }^{\circledR}$ green in PBS. Images (4OX) are representative of the cell population observed in the performed experiments. Images were obtained using an EVOS FL Cell Imaging System AMF4300, Life Technologies, USA. 
DT (1) induced mitochondrial damage. The effect of the tested compound on the mitochondria membrane potential was confirmed by confocal microscopy (Figure 4). Moreover, the tested drug could induce the depolarization of $(\Delta \Psi \mathrm{m})$ since the JC-1 dye remained in the cytoplasm in its monomeric form, shown as green fluorescence. The mitochondrial damage has been verified as well by quantifying the ATP level generated in $24 \mathrm{~h}$. We found out that the IC 90 produced a noticeable decrease in the total ATP level for both parasites (Figure 5). Furthermore, this effect was dramatically higher in T. cruzi with a level of produced ATP lower than $1 \%$ of ATP level produced in untreated cells.
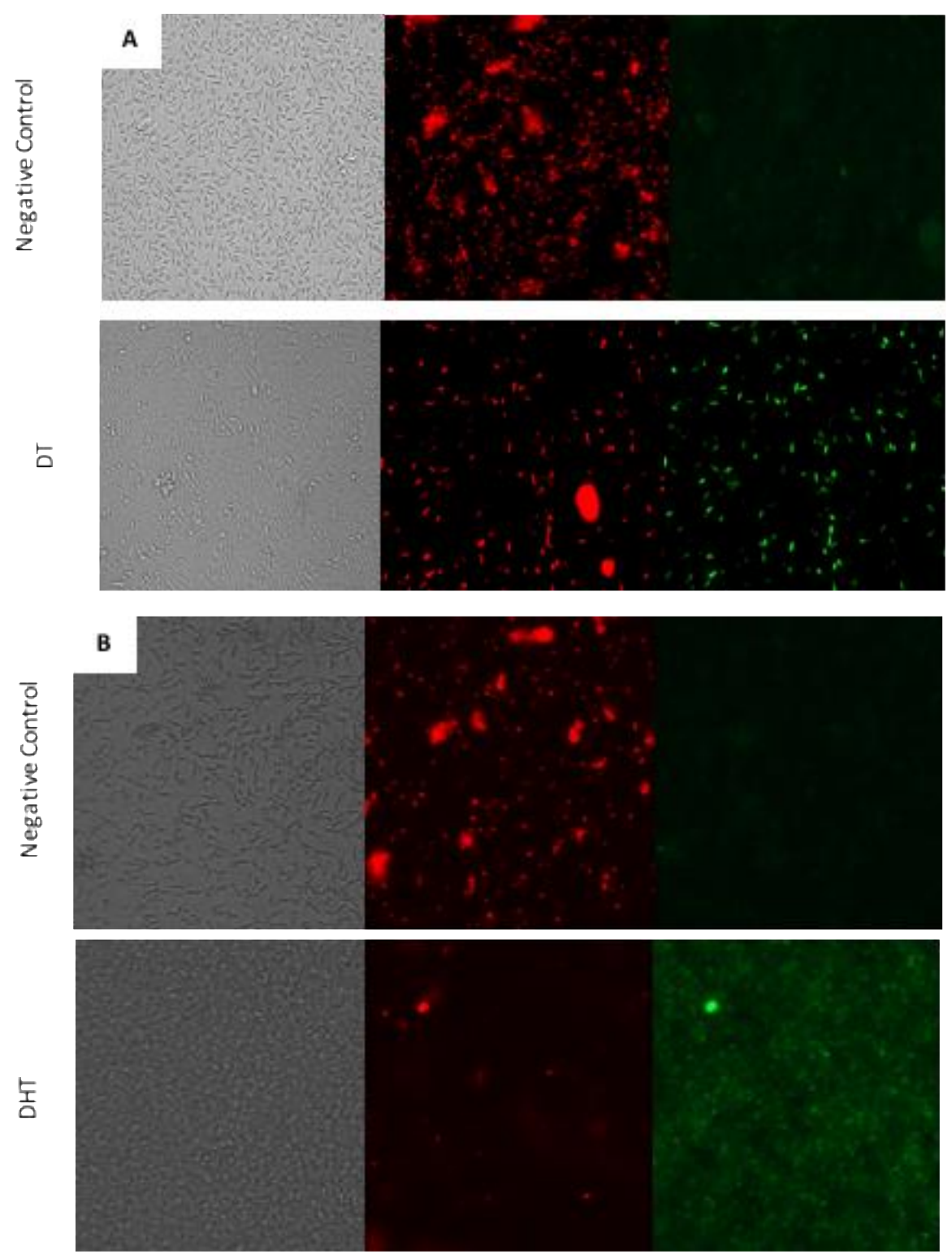

Figure 4: The effect of DT (1) on the mitochondrial membrane potential, in healthy cells, the JC-1 dye accumulates in the mitochondria as aggregates and emit a red fluorescence, meanwhile, in treated cells the dye remained as monomers in the cytoplasm and emit a green fluorescence. (A): Leishmania amazonensis; (B): Trypanosoma cruzi. Images (40X) are representative of the cell population observed in the performed experiments. Images were obtained using an EVOS FL Cell Imaging System AMF4300, Life Technologies, USA. 


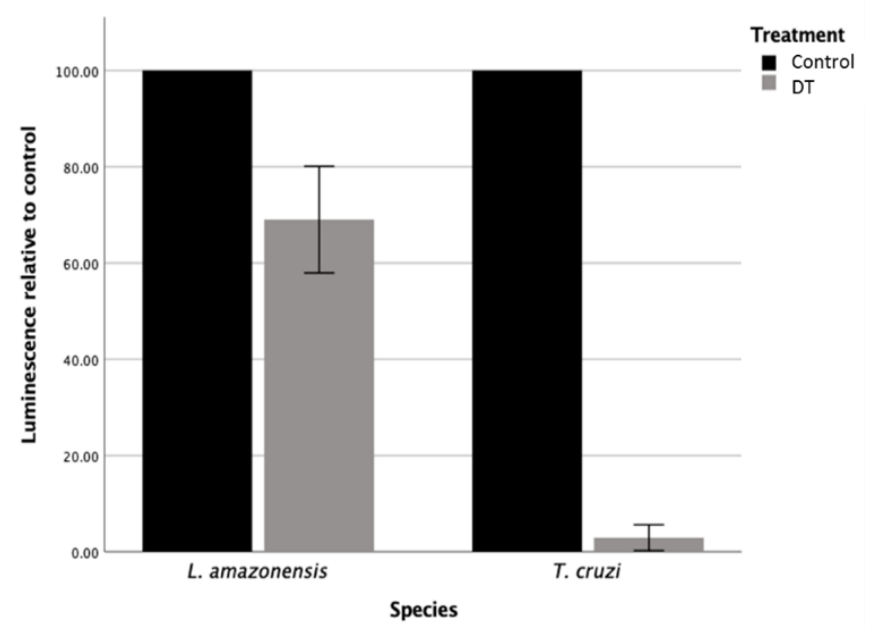

Figure 5. The effect of DT (1) on the ATP level of the parasites after $24 \mathrm{~h}$ of treatment. Data are expressed as percentage relative to control. ATP level was measured using a Cell Titer-Glo ${ }^{\circledR}$ Luminescent Cell Viability Assay (Promega).

There are many differences between the observed effects over both parasites that suggest an advanced death process for $T$. cruzi in comparison with an early stage of death for $L$. amazonensis after $24 \mathrm{~h}$ of treatment with DT (1). This is confirmed by the higher percentage of parasites stained with propidium iodide in the chromatin condensation assay, the lower level of ATP, and a higher percentage of parasites stained in green (low mitochondrial potential) in the JC-1 assay. In addition, this could be observed on the light transmitted images of the parasites, where the $T$. cruzi parasites look more rounded, smaller and damaged than the $L$. amazonensis ones.

\subsubsection{Analysis by Atomic Force Microscopy (AFM) of DT effects}

In order to establish the structural damage produced by DT (1), a detailed study using AFM was carried out on $T$. cruzi (Figure 6). For this purpose, a negative control of non-treated epimastigotes $\left(10^{5} \mathrm{cell} / \mathrm{mL}\right)$ were fixed in smears on a glass surface and the different parts of the parasite were analyzed using AFM. Control images clearly show an intact cell morphology, the flagellar pocket and a normal cell membrane. In the same way, epimastigotes treated with DT (1) at IC 90 for $24 \mathrm{~h}$ were equally processed and observed using AFM. The most representative images of the DT (1) effects on T. cruzi are summarized in Figure 7. Among the observed effects using this approach, it is important to highlight that key cellular events were observed in treated cells when compared to a non-treated control parasite, such as the loss of intracellular content including the kinetoplast. Moreover, the flagellar pocket was collapsed and the cellular membrane showed dramatic signs of blebbing as it can be observed in Figure 7. 

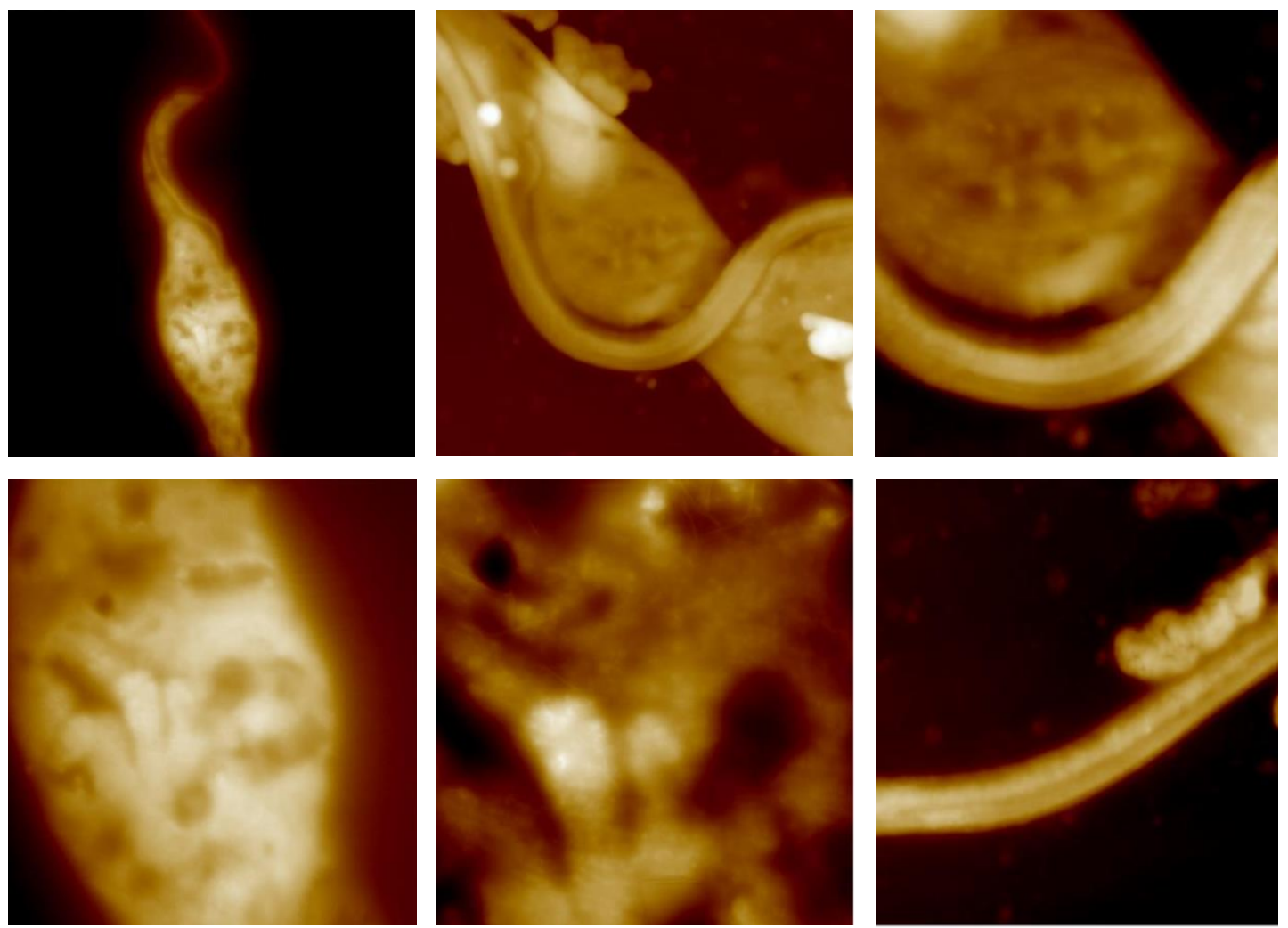

Figure 6. AFM image of epimastigotes of Trypanosoma cruzi. Details of the parasite and the flagella. Images size: top, left-right 20x20; 4x4; $2 \times 2 \mu \mathrm{mx} \mu \mathrm{m}$; bottom, left-right $6.1 \times 6.1 ; 3 \times 3 ; 2.7 \times 2.7 \mu \mathrm{m} \times \mu \mathrm{m}$ ).
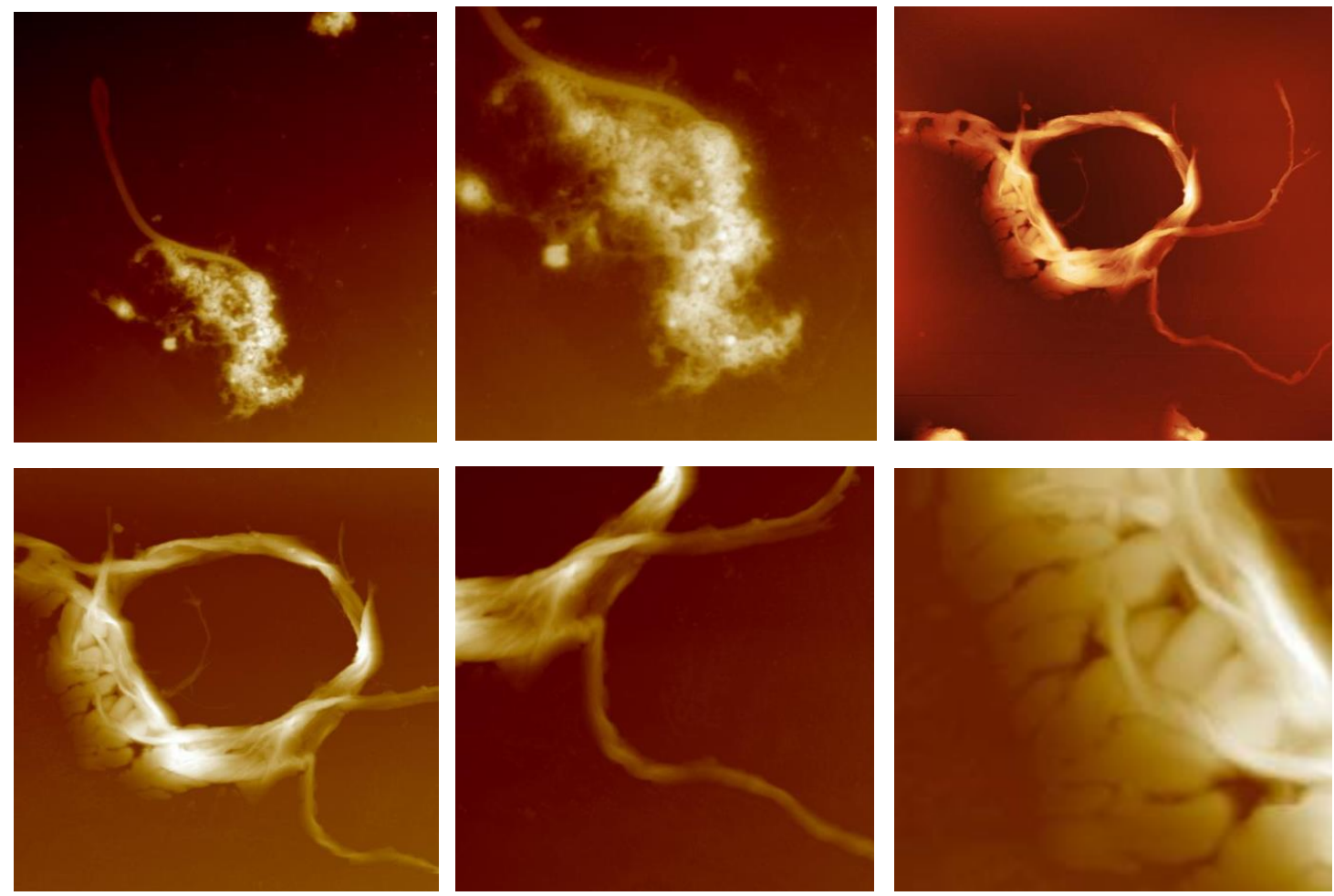

Figure 7. AFM image of epimastigotes of Trypanosoma cruzi treated with DT (1) IC $\mathrm{C}_{90}$ during $24 \mathrm{~h}$. Details of the parasite and the flagella. Images size: top, left-right $20 \times 20 ; 10.9 \times 10.9 ; 31.3 \times 31.3$; bottom, left-right $20 \times 20 ; 15 \times 15 ; 7.5 \times 7.5 \mu \mathrm{m} \times \mu \mathrm{m}$ ) 


\subsection{Structure-activity relationship analysis}

Among the metabolites tested against Leishmania and Trypnanosoma, eight showed activity against parasites (Table 1). A summary of the results from the structural point of view is represented in Figure 8. Also, the selective index of the most active compounds is shown in Table 2. The structure-activity relationship (SAR) discussion starts using the major compound in the alga, dehydrothyrsiferol (DT) (1), as model molecule due to its antiparasitic activity against the three-tested parasite models $L$. amazonensis; $L$. donovani and $T$. cruzi with $I_{50}$ of $8.36 \pm 0.77,28.26 \pm 1.74$ and $9.45 \pm 0.46 \mu \mathrm{M}$, respectively. Thus, the molecular fragments that imply active substances are embedded in different colors associated to the parasite species: L. amazonensis are in green squares; $L$. donovani in blue color and the molecules active against T. cruzi are marked in red. Simplifications in the size of the molecule as is the case of adejene B (11) (fragment C-1-C-14), and bromine losses as for 1,2-dehydropseudodehydrothyrsiferol (5) or nivariol A (10) lead to inactive substances. In the same way, chemical modifications carried out on DT (1): sulfonation at C-18 (e.g. 18-sulphatedehydrothyrsiferol (12)), as well as the diol formation at C-15-C-28 (e.g. 28-hydroxythyrsiferl (16)), led us to substances with no activity. On the other hand, the modification of the tetrahydrofuran terminal ring between C19 and $\mathrm{C}-22$ by a tetrahydropyran ring between C-19 and C-23 leads us to the most active and toxic compound against murine macrophage J774A.1, iubol (3). The sole oxidation of DT (1) at C-22 in 22-hydroxydehydrothyrsiferol (4) lead us to a less active substance against $L$. amazonensis than (1), with an $\mathrm{IC}_{50}$ of $34.65 \pm 6.08 \mu \mathrm{M}$ and inactive against $L$. donovani and $T$. cruzi. In the case of the additional introduction of a hydroxyl group at carbon C-15 (e.g. thysiferol (2)), it produces a total loss of activity. Moreover, oxidation at C-18 (e.g. 18ketodehydrothyrsiferol (13)) lead to a compound with antiparasitic properties against $L$. amazonensis; L. donovani and T. cruzi, but showing less effectivity than the model molecule.

The most interesting series of analogues from the SAR point of view is represented by the pentacyclic compounds 6-9, 14 and 15, with an additional tetrahydrofuran ring between $\mathrm{C}-15$ and $\mathrm{C}-18$. Thus, the intramolecular cyclization produced by attack of the oxygen at C-18 on C-15 leads to a mixture of epimers, saiyacenol A (6) and saiyacenol B (7). Compound 6 turned out to be active against $L$. amazonensis and $T$. cruzi with an $I_{50}$ of $12.96 \pm 1.84$ and $13.75 \pm 2.28 \mu \mathrm{M}$, respectively. However, its $15 R$-isomer, compound 7 , turned out to be slightly more active and selective against $L$. amazonensis, $I_{50} 10.32 \pm 1.09 \mu \mathrm{M}$, and inactive against $L$. donovani and T. cruzi. Oxidation at C-28 (e.g. 28-hydroxysaiyacenols A (8) and B (9)) produces a similar effect than in thyrsiferol (2) case, leading to molecules which lack antikinetoplastid activity. Finally, the introduction of a iodine atom at C-28 in this series leads to selective compounds against Leishmania species, 28-iodosaiyacenols A (14) and B (15). This modification turned out to be the most effective transformation obtaining a new lead, 28iodosaiyacenol B (15), with notable activity against L. amazonesis $\left(\mathrm{IC}_{50} 5.40 \pm 013 \mu \mathrm{M}\right)$ that turned out to be non-toxic against the murine macrophage cell line J774A.1 ( $\left.C_{50}>100\right)$. Its activity is comparable to that of the reference drug miltefosine $\left(\mathrm{IC}_{50} 6.48 \pm 0.24\right.$ and $\mathrm{CC}_{50} 72.19$ $\pm 3.06 \mu \mathrm{M}$ (Table 1; Figure 8).

In addition, the activity of DT (1) against the amastigote stage of $L$. amazonensis is better than miltefosine, showing an $\mathrm{IC}_{50}$ of $2.16 \pm 0.20 \mu \mathrm{M}$ for DT (1) compared with the $\mathrm{IC}_{50} 3.12 \pm$ 
$0.30 \mu \mathrm{M}$ of miltefosine. This stage of the parasite corresponds with that present in the host, being the infective form and causative of the pathology. However, the cytotoxicity of the compound does not allow DT (1) to improve the selectivity index of miltefosine. For T. cruzi, neither compound showed better activity than benznidazole, nor selectivity index, due to the low cytotoxic effect of benznidazole. Consequently, the results hereby presented confirm that secondary metabolites of the red alga $L$. viridis show great biological properties and adequate antiparasitic drugs may become available from them.

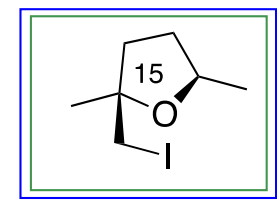

(14)

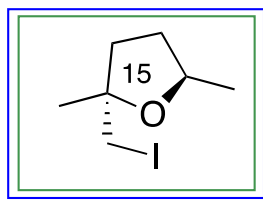

(15)

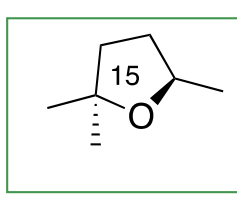

(7)

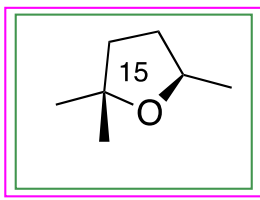

(6)<smiles>CC(CC[C@@H](O)[C@H]1CC[C@@H](C(C)(C)O)O1)C1CCC2OC([C@]3(C)CCC(Br)[C@@H](C)O3)CCC2(C)O1</smiles>

(13)

\section{Leishmania amazonensis}

Leishmania donovani

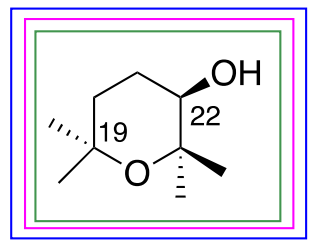

(3)

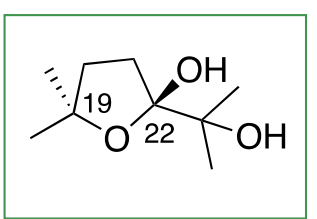

(4)

Figure 8. Structure activity relationship (SAR) for oxasqualenoids with antikinetoplastid properties based on the main metabolite DT (1) as lead molecule. Color squares correlate the active substances vs species.

Table 2. Selectivity Index $\left(\mathrm{SI}=\mathrm{CC}_{50} / \mathrm{IC}_{50}\right)$ of active oxasqualenoids and reference drugs against $L$. amazonensis, $L$. donovani and $T$. cruzi referred to toxicity against murine macrophage J774.A1.

\begin{tabular}{|c|c|c|c|}
\hline Compounds & $\begin{array}{l}\text { L. amazonensis } \\
\text { (Promastigote) }\end{array}$ & $\begin{array}{c}\text { L. donovani } \\
\text { (Promastigote) }\end{array}$ & $\begin{array}{c}\text { T. cruzi } \\
\text { (Epimastigote) }\end{array}$ \\
\hline 1 & 3.4 & 1.0 & 3.0 \\
\hline 3 & 1.1 & 0.4 & 0.8 \\
\hline 4 & 2.9 & NA & NA \\
\hline 6 & 4.6 & NA & 4.4 \\
\hline 7 & $>9.7$ & NA & NA \\
\hline 13 & 0.6 & 0.5 & 2.1 \\
\hline 14 & 1.4 & 0.9 & NA \\
\hline 15 & $>18.5$ & $>5.9$ & NA \\
\hline Miltefosine ${ }^{*}$ & 11.1 & 21.7 & - \\
\hline Benznidazole* & - & - & 57.6 \\
\hline
\end{tabular}

NA: Not active at the maximum concentration tested.

\section{Experimental section}

\subsection{General methods}

All reagents were commercially available and used as received. All solvents were dried and distilled under argon immediately prior to use or stored appropriately. Flash 
chromatography was performed with silica gel (230-400 mesh) as the stationary phase and mixtures of $n$-hexane and EtOAc, in different proportions given in each case, as the mobile phase. EnSpire Multimode Reader (Perkin Elmer, Waltham, MA, USA) using absorbance values of Alamar Blue reagent (Bio-Rad Laboratories, Oxford, UK). TLC was performed on AL Si gel. TLC plates were visualized by UV light $(254 \mathrm{~nm})$ and by adding a phosphomolybdic acid solution $10 \mathrm{wt} \%$ in $\mathrm{MeOH}$ or a vanillin solution ( $6 \mathrm{~g}$ of vanillin, $450 \mathrm{~mL}$ of EtOH, $40 \mathrm{~mL}$ of $\mathrm{AcOH}$, and $30 \mathrm{~mL}$ of $\mathrm{H}_{2} \mathrm{SO}_{4}$ ).

\subsection{Isolation of Laurencia metabolites and chemical transformations}

Natural metabolites were isolated from the seasonal red alga Laurencia viridis by annual harvestings between April 2013 - April 2018 at Paraiso Floral, Tenerife, Canary Islands $\left(28^{\circ} 07^{\prime} 12^{\prime \prime} \mathrm{N}, 16^{\circ} 46^{\prime} 45^{\prime \prime} \mathrm{W}\right)$. Dried material of different parts of alga was filed at TFC Phyc 7180 (Herbario de la Universidad de La Laguna, Departamento de Biología Vegetal, Botánica, Tenerife, Spain).

Standard procedure for the isolation of marine polyether triterpenoids starting by extraction of dry alga $L$. viridis with $\mathrm{CHCl}_{3}: \mathrm{MeOH}(1: 1)$ at room temperature (rt), and a dark green, viscous oil were obtained after concentration under reduced pressure. The extracts were first chromatographed on Sephadex $\mathrm{LH}-20(7 \times 50 \mathrm{~cm})$ using $\mathrm{CH}_{2} \mathrm{Cl}_{2}: \mathrm{MeOH}(1: 1)$ as the mobile phase. The oxasqalenoid fractions were subsequently processed on a silica gel column with $n$-hexane:EtOAc (80:20-20:80) and medium-pressure chromatography was done on Lobar LiChroprep Si-60 using $\mathrm{CH}_{2} \mathrm{Cl}_{2}$ :acetone (8:2) at $1 \mathrm{~mL} / \mathrm{min}$. Final purification was done on a HPLC with a $\mu$-Porasil column using $n$-hexane:EtOAc:MeOH, 18:15:5 to yielded pure compounds: dehydrothyrsiferol (DT) (1); thyrsiferol (2); iubol (3); 22-hydroxydehydrothyrsiferol (4); 1,2 dehydropseudodehydrothyrsiferol (5); saiyacenols $A$ and $B$ (6 and 7); 28-hydroxysaiyacenol A y B (8 and $\mathbf{9})$; nivariol A (10) and the truncated metabolite adejene B (11) were obtained for the biological assays. 18-sulphatedehydrothyrsiferol (12); 18ketodehydrothyrsiferol (13); 28-iodosaiyacenols A and B (14 and 15) and 28hydroxythyrsiferol (16) were prepared from the main metabolite DT (1) using the methodology previously described [16], and purified by HPLC with a $\mu$-Porasil column using $n$ hexane:EtOAc:MeOH, 18:15:5.

\subsection{Parasite strain}

The activity of different compounds was evaluated against promastigotes and amastigote stage of L. amazonensis (MHOM/BR/77/LTB0016) and epimastigote $T$. cruzi (Y strain). Cytotoxicity assays of the active molecules was tested against the macrophage J774A.1 cell line, cultured in RPMI 1640 medium supplemented with $10 \%$ fetal bovine serum at 37 ㅇ $\mathrm{C}$ and $5 \% \mathrm{CO} 2$ atmosphere. Promastigotes of both strains of Leishmania were cultured in Schneider's medium (Sigma-Aldrich, Madrid, Spain) supplemented with $10 \%$ fetal bovine serum at $26^{\circ} \mathrm{C}$ and were grown to the log phase per previous methods for use in further experiments. For some of the assays, the parasites were also cultured in RPMI 1640 medium (Gibco), with or without phenol red. Epimastigotes of both strains were cultured in Liver Infusion Tryptose (LIT) medium supplemented with $10 \%$ fetal bovine serum at $26^{\circ} \mathrm{C}$ and were grown to the log phase for use in further experiments. 


\subsection{Evaluation of leishmanicidal, trypanocidal and cytotoxic activities}

\subsubsection{Leishmanicidal capacity assay}

Logarithmic phase cultures of promastigote stage of L. amazonensis were used for experimental purposes, and the in vitro susceptibility assay was performed in sterilized 96well plates. 106/well parasites were added to wells containing different concentration of the drug to be tested. Percentages of inhibition, $50 \%$ inhibitory concentrations $\left(\mathrm{IC}_{50}\right)$ for active compounds were calculated by linear regression analysis using the alamarBlue ${ }^{\circledR}$ method [18]. Subsequently, the most active molecules were tested against the intra-macrophages stage of L. amazonensis.

The anti-amastigote activity was measured according to Jain et al, (2012). Macrophages of the J774A.1 cell line were placed in a 96-well flat bottom plate at a density of $2 \times 10^{5} / \mathrm{mL}$ in RPMI supplemented with $10 \% \mathrm{SBF}$ and was incubated for an hour at $37{ }^{\circ} \mathrm{C}$ in a $5 \%$ $\mathrm{CO}_{2}$ environment to allow almost complete differentiation of the cells. $100 \mu \mathrm{L}$ of stationary phase promastigotes ( 7 days old culture) were added in a 10:1 ratio and the cultures ( $2 \times$ $106 / \mathrm{mL}$ ) and were re-incubated at $37^{\circ} \mathrm{C}$ for $24 \mathrm{~h}$ to allow a maximum infection. After the incubation, the excess of promastigotes was washed off with the same medium at least 3 times. $50 \mu \mathrm{L}$ of the culture medium (RPMI-1640 with 10\% FBS) were added into each well. In the same time, a serially dilution of the test compounds was made in a 96-deep well plate with the same medium, and then $50 \mu \mathrm{L}$ of this serially-diluted standard were added to each well. The plates were incubated at $37^{\circ} \mathrm{C}, 5 \% \mathrm{CO}_{2}$ for $24 \mathrm{~h}$. After this incubation, we remove the medium from each well and add $30 \mu \mathrm{L}$ of Schneider (with $0.05 \%$ SDS) was added to each well. The plate was shacked for $30 \mathrm{~s}$ and $170 \mu \mathrm{L}$ of Schneider medium were added to each well. alamarBlue at $10 \%$ was added into each well of the 96 -well plates and incubated at $26^{\circ} \mathrm{C}$ for $72 \mathrm{~h}$ to allow the transformation of rescued amastigote to promastigotes. After overnight incubation, the plates were read in a spectrofluorimeter at $544 \mathrm{~nm}$ excitation, $590 \mathrm{~nm}$ emission.

\subsubsection{Trypanocidal capacity assay}

The activity was evaluated in vitro against epimastigote stage of $T$. cruzi. Different concentrations of fractions and compounds were incubated in 96 wells plate for 96 hours with a density of $10^{5}$ parasite/well. $10 \%$ of alamarBlue ${ }^{\circledR}$ was added to each well and the $\mathrm{IC}_{50}$ was calculated. All assays have been realized in triplicate.

\subsubsection{Cytotoxicity assay}

The cytotoxicity of active compounds was evaluated in J774A.1 macrophages cell line. Serial dilution of compounds 1-6 were plated and incubated with the appropriate cell concentration of macrophages. After $24 \mathrm{~h}$ cell viability was determined using alamarBlue ${ }^{\circledR}$ method using dose response curves to obtain the $\mathrm{CC}_{50}$. [19].

\subsection{Mechanisms of cell death}

\subsubsection{Chromatin condensation determination}

A double-stain apoptosis detection kit (Hoechst 33342/PI) (GenScript, Piscataway, NJ, USA) and an EVOS FL Cell Imaging System AMF4300, Life Technologies, USA were used. The 
experiment was carried out by following the manufacturer's recommendations, briefly, after being treated with IC90 of the tested molecules for $24 \mathrm{~h}$, cells were centrifuged (1500 rpm. for $10 \mathrm{~min}$ ) washed twice with PBS (phosphate buffered saline) buffer. The double-staining pattern allows the identification of three groups in a cellular population: live cells will show only a low level of fluorescence, cells undergoing PCD will show a higher level of blue fluorescence (as chromatin condenses), and dead cells will show low-blue and high-red fluorescence (as the Propidium lodide stain enters the nucleus).

\subsubsection{Plasma membrane permeability}

The SYTOX ${ }^{\circledR}$ Green assay was performed to detect membrane permeability alterations of parasites. Briefly, $1 \times 107$ parasites $/ \mathrm{mL}$ were washed and incubated in PBS with the of SYTOX ${ }^{\circledR}$ Green at a final concentration of $1 \mu \mathrm{M}$ (Molecular Probes) for $15 \mathrm{~min}$ in the dark at room temperature. Subsequently the tested compounds were added at IC90 concentration. The increase in fluorescence due to binding of the fluorescent marker to the parasitic DNA was observed in an EVOS FL Cell Imaging System AMF4300, Life Technologies, USA.

\subsubsection{Analysis of Mitochondrial Membrane Potential}

The collapse of an electrochemical gradient across the mitochondrial membrane during apoptosis was measured using a JC-1 Mitochondrial Membrane, Potential Assay Kit, Cayman Chemical. After being treated with $\mathrm{IC}_{90}$ concentration of the tested molecules for $24 \mathrm{~h}$, the promastigotes were centrifuged ( $1500 \mathrm{rpm} . \times 10 \mathrm{~min}$ ) and suspended in JC-1 buffer. After that, $100 \mu \mathrm{L}$ of each treated culture was added to a black 96 well plate (PerkinElmer) than $10 \mu \mathrm{L}$ of JC-1 was added and incubated at $26^{\circ} \mathrm{C}$ for $30 \mathrm{~min}$. Analysis for mean green and red fluorescence intensity was done using an Enspire microplate reader (PerkinElmer, Massachusetts, USA) for 30 minutes. In addition, the depolarization of the mitochondrial membrane potential was confirmed by microscopic observation using EVOS FL Cell Imaging System AMF4300, Life Technologies, USA.

\subsubsection{Measurement of ATP}

ATP level was measured using a Cell Titer-Glo ${ }^{\circledR}$ Luminescent Cell Viability Assay (Promega). The effect of the drug on the ATP production was evaluated by incubating $\left(10^{7}\right.$ cells $/ \mathrm{mL}$ ) with the previously calculated IC 90 of the tested molecules.

\subsection{Atomic Force Microscopy (AFM) analysis}

A culture of $T$. cruzi was incubated with DT (1) at final concentration IC 90 for $24 \mathrm{~h}$. After the incubation, $10 \mu \mathrm{L}$ of the culture contained $10^{5}$ cell $/ \mathrm{mL}$ was smeared on glass slides. Samples were dried during $10 \mathrm{~min}$ before AFM analysis. AFM topographic images were obtained in Peak Force mode using a multimode microscope with a Nanoscope $V$ control unit from Bruker. Scan rates of $0.5-1.2 \mathrm{~Hz}$ and FESP (50-100 kHz, and 1-5 N m-1) tips (from Bruker) were used. To get representative information about the damage process in $T$. cruzi caused by DT (1), images from $(100 \mu \mathrm{m} \times 100 \mu \mathrm{m})$ to $(0.6 \mu \mathrm{m} \times 0.6 \mu \mathrm{m})$ were recorded using 512 points/line. 


\subsection{Statistical analysis}

The Percentage of inhibition and $50 \%$ inhibitory concentration $\left(\mathrm{IC}_{50}\right)$ and the cytotoxicity concentration were determined by non-linear regression analysis with $95 \%$ confidence limits. All experiments were performed three times each in duplicate and the mean values were also calculated. A Turkey test was used for analysis of the data. Values of $p<0.05$ were considered significant. The one-way ANOVA statistical analysis was undertaken using the SPSS Statistics 25.

\section{Acknowledgments}

This work was funded by INTERREG-MAC/1.1b/042 (BIOTRANSFER2) and PI18/01380 from Instituto de Salud Carlos III, Spain and RICET [RD16/0027/0001 project, from Programa Redes Temáticas de Investigación Cooperativa, FIS (Ministerio Español de Salud, Madrid, Spain), FEDEDR. IS, ALA and ARDM were funded by the Agustín de Betancourt Programme (Cabildo de Tenerife - ULL). Authors acknowledge the use AFM Service of General Research Support Services of University of La Laguna (SEGAI-ULL).

\section{References}

1.- WHOlWorld Health Organization. Neglected tropical diseases. 2019. http://www.who.int/neglected_diseases/diseases/en/. Accessed Apr 19, 2019.

2.- Rao, S. P. S., Barrett, M. P., Dranoff, G., Faraday, C. J., Gimpelewicz, C. R., Hailu, A., Jones, C. L., Kelly, J. M., Lazdins-Helds, J. K., Mäser, P., Mengel, J., Mottram, J. C., Mowbray, C. E., Sacks, D. L., Scott, P., Späth, G. F., Tarleton, R. L., Spector, J. M., Diagana, T. T. Drug discovery for kinetoplastid diseases: Future directions. ACS Infect. Dis. 5 (2019), 152-157.

3.- P.L. Bustos, N. Milduberger, B.J. Volta, A.E. Perrone, S.A. Laucella, J. Bua. Trypanosoma cruzi infection at the maternal-fetal interface: Implications of parasite load in the congenital transmission and challenges in the diagnosis of infected newborns. Frontiers in Microbiology 10, (2019) 1250. doi: 10.3389/fmicb.2019.01250.

4.- J.J. Fernández, M.L. Souto, M. Norte. Marine polyether triterpenes. Nat. Prod. Rep. 17 (2000), 235-246.

5.- $\quad$ M.L. Souto, C.P. Manríquez, M. Norte, F. Leira, J.J. Fernández, The Inhibitory effects of squalene-derived triterpenes on protein phosphatase PP2A. Bioorganic and Medicinal Chemistry Letters 13 (2003) 12611264.

6.- $\quad$ M.K. Pec, A. Aguirre, K. Moser-Thier, J.J. Fernández, M.L. Souto, J. Dorta, F. Díaz-González, J. Villar, Induction of apoptosis in estrogen dependent and independent breast cancer cells by the marine terpenoid dehydrothyrsiferol. Biochemical Pharmacology 65 (2003) 1451-1461.

7.- $\quad$ M.K. Pec, M. Artwohl, J.J. Fernández, M.L. Souto, D. Álvarez de la Rosa, T. Giraldez, A. Valenzuela-Fernández, F. Díaz-González, Chemical modulation of VLA integrin affinity in human breast cancer cells. Experimental Cell Research 313 (2007) 1121-1134.

8.- $\quad$ F. Cen-Pacheco, J.A. Villa-Pulgarin, F. Mollinedo, M. Norte, A.H. Daranas, J.J. Fernández, Cytotoxic oxasqualenoids from the red alga Laurencia viridis. European Journal of Medicinal Chemistry 46 (2011) 3302-3308.

9.- $\quad$ A.G. González, J.M. Arteaga, J.J. Fernandez, J.D. Martin, M. Norte, J.Z. Ruano, Terpenoids of rhe Red Alga Laurencia Pinnatifida. Tetrahedron 40 (1984) 2751-2755.

10.- J.W. Blunt, M.P. Hartshorn, T.J. McLennan, M.H.G. Munro, W.T. Robinson, S.C. Yorke, Thyrsiferol: a squalene-derived metabolite of Laurencia thyrsifera. Tetrahedron Lett., 19 (1978) 69-72. doi:10.1016/S0040-4039(01)88986-3.

11. F. Cen-Pacheco, J.A. Villa-Pulgarin, F. Mollinedo, M. Martín, J.J. Fernández, A.H. Daranas, New polyether triterpenoids from Laurencia viridis and their biological evaluation. Mar. Drugs 9 (2011) 2220-2235. doi:10.3390/md9112220. 
12. F. Cen-Pacheco,F. Mollinedo, J.A. Villa-Pulgarin, M. Norte, J.J. Fernández, A.H. Daranas, Saiyacenols A and B: the key to solve the controversy about the configuration of aplysiols. Tetrahedron 68 (2012) 7275-7279. doi:10.1016/j.tet.2012.07.005

13. F. Cen-Pacheco, A.J. Santiago-Benítez, C. García, S.J. Álvarez-Méndez, A.J. Martín-Rodríguez, M. Norte, V.S. Martín, J.A. Gavín, J.J. Fernández, A.H. Daranas, Oxasqualenoids from Laurencia viridis: Combined spectroscopic-computational analysis and antifouling potential. J. Nat. Prod. 78 (2015) 712-721. doi:10.1021/np5008922.

14. F. Cen-Pacheco, J. Rodríguez, M. Norte, J.J. Fernández, A.H. Daranas, Connecting discrete stereoclusters by using DFT and NMR spectroscopy: the case of nivariol. Chem. Eur. J. 19 (2013), 8525-8532. doi:10.1002/chem.201204272.

15. F. Cen-Pacheco, L. Nordström, M.L. Souto, M.N. Martín, J.J. Fernández, A.H. Daranas, Studies on polyethers produced by red algae. Mar. Drugs 8 (2010) 1178-1188. doi: 10.3390/md8041178.

16. J. Lorenzo-Morales, A.R. Díaz-Marrero, F. Cen-Pacheco, I. Sifaoui, M. Reyes-Batlle, M.L. Souto, A. H. Daranas, J.E. Piñero, J.J. Fernández, Evaluation of oxasqualenoids from the red alga Laurencia viridis against Acanthamoeba. Mar. Drugs 17 (2019) 420. doi-10.3390/md17070420.

17. A. López-Arencibia, D. García-Velázquez, C.M. Martín-Navarro, I. Sifaoui, M Reyes-Batlle, J. LorenzoMorales, In Vitro Activities of Hexaazatrinaphthylenes against Leishmania spp. Antimicrob. Agents Chemother. 59 (2015) 2867. doi: 10.1128/AAC.00226-15.

18. I. Sifaoui, A. López-Arencibia, C.M. Martín-Navarro, N. Chammem, M. Reyes-Batlle, M. Mejri, J. Lorenzo-Morales, M. Abderabba, J.E. Piñero, Activity of olive leaf extracts against the promastigote stage of Leishmania species and their correlation with the antioxidant activity. Experimental Parasitology 141 (2014) 106-111

19. H. Fadel, I. Sifaoui, A. López-Arencibia, M. Reyes-Batlle, S. Hajaji, O. Chiboub, I.A. Jiménez, I.L. Bazzocchi, J. Lorenzo-Morales, S. Benayache, J.E. Piñero, Assessment of the antiprotozoal activity of Pulicaria inuloides extracts, an Algerian medicinal plant: leishmanicidal bioguided fractionation. Parasitol. Res. 117 (2018) 531-53. 